\title{
Dentists in England relieved to re-open but key questions remain
}

The British Dental Association (BDA) has welcomed news the government has given the green light for the restoration of routine care services in England, but has cautioned that practices will need to move at different rates depending on availability and fitting of PPE, their ability to enact ongoing social distancing measures and time to implement appropriate crossinfection control.

NHS England and the Chief Dental Officer confirmed any practice that feels it is appropriately prepared can provide patient care from 8 June. This could see varying levels of treatments made available with immediate effect, with individual practitioners exercising their professional judgement on the pace of change.

The pace at which patient care can begin will be determined by a number of issues, such as stock levels of PPE. The availability of and ability to fit test 'higher end' PPE in particular may limit the universal restoration of a full range of dental care. The BDA has expressed the view that steps should be taken to integrate dentistry into the wider government strategy on PPE supply led by Lord Deighton.

Dentist leaders have also warned the whole business model that the service is based on could change unalterably upon reopening, with social distancing and cross-infection control reducing capacity and potentially access levels by as much as two thirds.

The BDA is continuing to press for the NHS contractual framework to reflect the new reality and for additional support for private dentistry, including a business rates holiday - already offered to leisure and retail sectors - to be expanded to dental practices, alongside other support to mitigate against reduced patient numbers.

BDA Chair Mick Armstrong said: 'A return of high street dentistry we will be welcome news to millions of patients left with few options during lockdown, but key questions remain.

'It is right to allow practices to decide themselves when they are ready to open. Dentists will be keen to start providing care as soon as safely possible, but we will need everyone to be patient as practices get up and running.

'Dentist can open their doors but won't be able to provide a full range of care without the necessary kit. Longer term practices can only stay afloat with ongoing support, while social distancing continues and the costs of providing care are sky high.

'Opening the floodgates risks raising false expectations, unless government is willing to step up and help.'

\section{BDJ $\frac{\text { RESEARCH INSIGHTS }}{\text { FOR ANOTHER VIEW }}$}

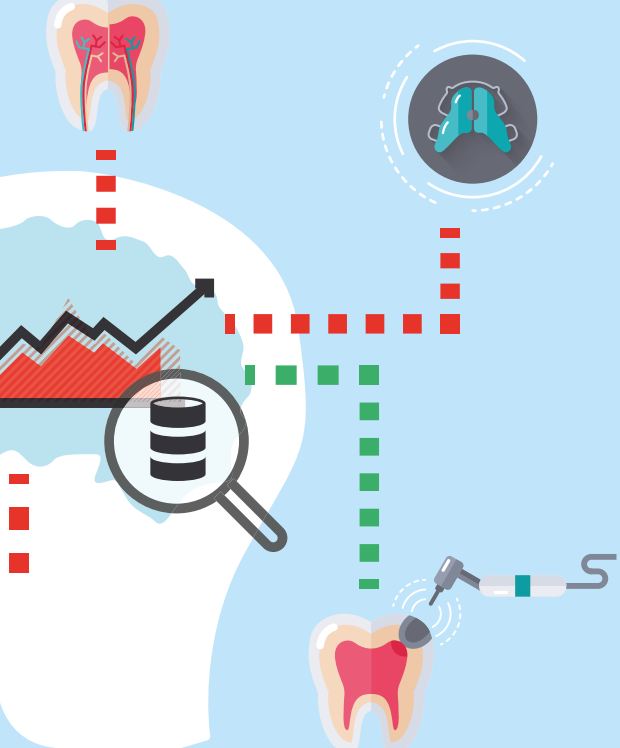

- Research insights from across the BDJ Portfolio

- Providing busy readers with valuable context including article summaries and expert commentary

Catch up here: http://bit.ly/BDJResearchlnsights 